\title{
European Diversity: Regional Innovation Potential in Transportation
}

\author{
Merja L. Hoppe and Martin Winter \\ School of Engineering, Zurich University of Applied Sciences, Winterthur 8401, Switzerland
}

\begin{abstract}
Transportation is essential for European competitiveness. While the transportation system guarantees location quality for the economy and citizens, the transportation industry provides jobs and strengthens the economy in general. Recently, the transportation sector has had to face challenges arising from new developments. Investments had to be limited due to the financial and economic crisis, new competitors are arising on the global market, climate change requires action affecting transportation and European regional disparities need to be overcome, especially when it comes to transportation. The change requires new strategies to be adopted to and also to actively shape the process. The European Commission aims to support the transportation sector by promoting innovation on a regional level. To ensure successful effects of funding, financial support should not be spread but be focused on regions of highest innovation potential in transportation. The project METRIC, funded by the 7th Framework Programme of the European Union, has developed a method to measure innovation potential in transportation, applying it to the regions in Europe. The results should be served as a basis for funding distribution and should also identify certain types of regional innovation patterns. An analytical approach to measuring the innovation potential in the transportation sector has been developed. Based on this, empirical analysis has been done. Results show different principles of innovation, a strong dependency on both the historical path of economic development of regions and countries and the recent economic situation. While innovation potential in the transport industries could be analysed, transport service is different. As this sector bears a huge potential for process innovation, which could increase energy efficiency and reduce emissions, there is a need of further research in services innovation.
\end{abstract}

Key words: Innovation, innovation potential, transport, funding, Europe, transformation, disparities.

\section{Introduction}

The European transport sector is facing challenges due to fundamental changes in the framing conditions. Mobility and traffic demands have increased over the last few decades and this trend is expected to continue. While this trend is related to economic growth, it also brings more negative aspects, e.g., effects on sustainability. Different needs and effects which lead to ambiguous/contradictory environmental, social and economic consequences are shown:

- On the environmental side, there is a need to reduce the negative impact of transport and mobility concerning energy consumption, as well as greenhouse gas emissions and noise;

Corresponding author: Merja L. Hoppe, Ph.D., research fields: sustainable development, mobility, transport, regional development and future studies. E-mail: Merja.hoppe@zhaw.ch.
- Economy requires transport in order to support competitiveness of the whole economy by an optimized infrastructure and the transport industry itself;

- On the social side, transport has to provide accessibility which is affordable to all to overcome European socio-economic disparities, ensuring inclusive mobility. This is in fact closely related to transportation providing the basic infrastructure for regional economy and accessibility of jobs, as well as employment opportunities in related industries;

- At the same time, the cost of maintenance for infrastructure exceeds public financial resources. Due to the financial crisis, lower tax revenues, increasing cost for infrastructure and investments in transportation had to be limited. A high quality of mobility and accessibility has to be provided to strengthen location quality and support the economy 
and job creation;

- The competitive landscape in the transportation sector is changing due to a shift of demand, technical development and production to Asian and other upcoming competitors.

There is a need to react to the changing frame conditions and the related requirements. The European transportation sector not only has to successfully adapt to these changes but also needs to develop strategies to actively shape the process of change. Due to the size of the challenge, a transformation process, also a fundamental, socio-economic and political change, is necessary to address the related problems adequately. Consequently, actors from policy, planning and industry have to find strategies to cope with the changing environment. In this context, innovation is seen as a driver to support renewal to ensure economically, environmentally and socially sustainable transport. By developing new products, services and mobility concepts and regionally unique selling points could be developed to strengthen economic competitiveness. Thus both regional disparities in transportation infrastructure and industries are crucial for European development.

Innovation policy aims to support the industrial innovation by providing funding on a regional basis. In this context, the EU (European Union), in particular, has to tackle the problem of how to address funding in regions and industries with innovation potential rather than distributing money for political reasons. To increase the effectiveness of funding, there is a need to identify the innovation potential of regions related to special industries.

The aim of the EU-funded project METRIC was to develop a method to measure the innovation potential of a particular industry (transport) in a particular region. From this, the question arose as to whether it is worthwhile to invest in the particular sector and stimulate economic power and prosperity. This paper describes both the approach that was developed and the results of the innovation potential analysis, including the identification of principles for innovation on a regional base along with regional innovation types. Analysis based on statistical data provides empirical evidence, which at the same time is limited due to data availability.

\section{Transportation and Innovation as an European Challenge}

As policy has to react to the challenges, funding for innovation in transport is seen as a potential solution for reducing energy consumption and greenhouse gas emissions while at the same time providing a high level of mobility and increasing economic competitiveness [1], especially addressing innovative clusters. Industrial clusters are seen as innovation machines strengthening regional and general economic competitiveness in regions (general aspects, e.g., Gnyawali and Srivastava [2]). A problem arises as innovation is based on specific knowledge, unique development and a particular style of business organization. Thus there is no "one-fits-all" solution. There is a need for a better understanding of the nature of regional innovation and specific regional factors for innovation.

At the same time, European funding decisions need formalized methods of regional comparison in order to avoid case-by-case decisions but to provide a standardized method and transparent process of decision-making. To make best use of funding, policy has to address specific innovation by deciding on potential success of an individual development path for innovation for different regions based on their specific frame conditions. European regions show great disparities concerning economic structure, dynamic and innovation potential. Effective funding has to consider this. At the same time, due to the size of Europe, individual funding is difficult to implement-A certain level of generalization is needed to support European transport successfully on a regional level. Thus, as well as understanding innovation in transport and on a regional level, there is 
also a need for innovation in policy, which means that common ways of policy making have to be questioned in themselves and new ways to put policy into practice have to be found. The method described here is designed to provide a method to measure innovation potential for the transport sector on a regional basis by comparing European regions in a standardized way and considering European disparities at the same time.

\section{Measuring Regional Innovation Potential}

Related to the aim of identifying regions with a high innovation potential and to promote these regions individually, the methodological approach was based on the EU concept for regional innovation. Two aspects had to be considered as basic prerequisites:

- Dealing appropriately with regional disparities within the EU;

- Developing a method to measure innovation potential in transport on a regional level.

Previously, innovation in Europe on a regional basis was measured generally, without a specific industry in view; This was done with a tool provided by the EU, mainly scoring individual indicators that are directly related to innovation - the RIS (Regional Innovation Scoreboard). In the METRIC project, the tool was further developed and adjusted to measure innovation in particular industries (semi-colon after industries), that is, for the transport industry to the RIST (Regional Innovation Scoreboard Transport). The new approach consists of a 3 -stage process.

\subsection{Regional Disparities}

Due to the socio-economic differences within Europe, regions should not be comparatively analysed as a whole; Regions might not be able to catch up with leading European transportation clusters, even if they might have potential for innovation on a lower but viable level. Thus the first stage involves a pre-classification of regions according to their general economic level into three groups, with each reflecting a certain socio-economic level. This allows a comparison of every region in Europe within a group of equal or even similar preconditions. The European Commission used the GDP (gross domestic product) per head as a basis to distinguish different regional economic levels and to determine the necessity of funding in every European region [3]. In METRIC, the method was used to distinguish among three types of European regional levels: "more-developed regions", "transition regions" and "less-developed regions" (Fig. 1).

According to the classification method, "more-developed regions" report over $90 \%$ of the EU-average of the GDP, while the "transition" category reports between $75 \%$ and $90 \%$ of the EU-average and "less-developed regions" are lower than $75 \%$ of the EU-average [3]. The categorization was used to compare regions within their groups in the following innovation potential analysis.

\subsection{Measurements on Regional Innovation Potential in Transport}

When developing a method, one has to face the challenge of limited availability of innovation-specific data for the transport sector, especially when it comes to regionalized data. METRIC reverted to existing innovation indicators used by the European Commission while modified and adapted the indicators to transport.

The European Commission developed the so-called "IUS" (Innovation Union Scoreboard) as a tool to measure general innovation on a country or NUTS-1 level ("NUTS" stands for "Nomenclature des Unités Territoriales Statistiques"). A set of 25 indicators and eight innovation dimensions allows us to measure and compare innovation [4]. For regional scales of NUTS-2 level, the European Commission has created the "RIS". As not all data used for the IUS indicators are available on a regional level, the scoreboard uses 12 indicators out of the 25 indicators of the IUS. The RIS subset covers the areas of human resources, education, research and development, funding and 


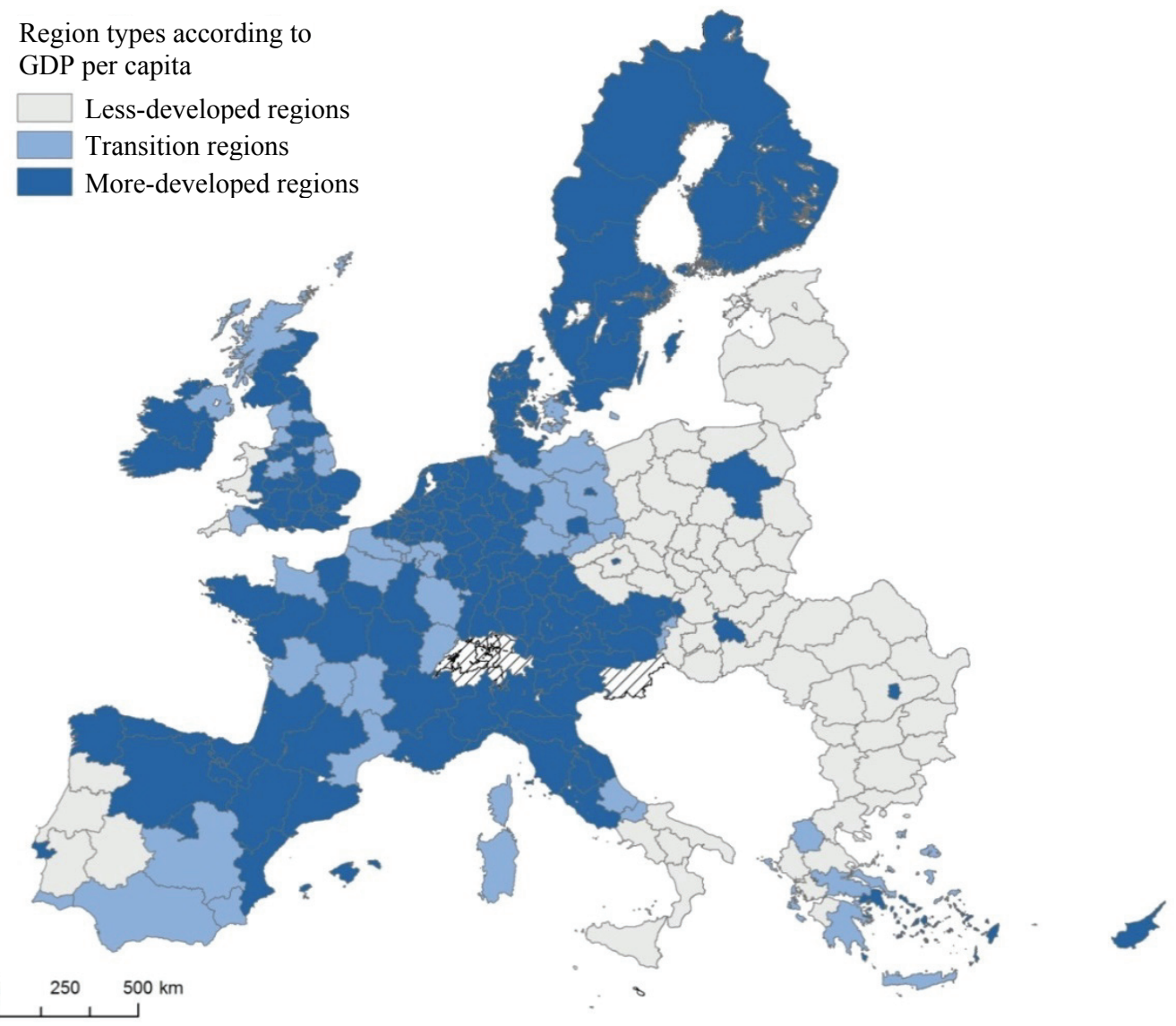

Fig. 1 Typology of NUTS-2 regions [3].

investments, patents, as well as economic effects [5].

As the METRIC project aims to measure regional innovation focused on transport, the RIS-approach, measuring innovation in general, had to be modified to be adopted to transport. Since the EU has no tool focused on transport, the METRIC project created an "RIST", based on RIS. The new scoreboard includes 10 different indicators using the same structure and concept as RIS. Each indicator was selected from the Eurostat database with particular attention paid to the fact that the innovation potential is to be measured. Every indicator is related to the transport sector in order to get the branch-specific innovation potential score. RIST (similar to IUS and RIS) uses indicators classified in three groups related to different aspects of innovation, with each reflecting special aspects of innovation: (1) enabler; (2) firm activities; (3) outputs:

(1) The enabler indicator group "captures the main drivers of innovation performance external to the firm" [4] using data on human resources, research systems and funding:

- share of government R\&D (research and development) spending on transport in percentage;

- share of highly-educated (tertiary level) persons employed in the transport sector (including all manufacturing and services);

- share of persons employed in science and technology in the transport sector (including all manufacturing and services);

- employment in technology and knowledge-intensive sectors in the transport sector;

(2) The firm activities group of indicators reflects the innovation efforts, including firm investments, entrepreneurship and intellectual assets [4]. The firm activities of the RIST group consist of the following indicators: 
- average number of patents per year per 100,000 employees in the transport sector;

- share of innovative enterprises (which introduce product/process innovation every year) in the transport sector;

- share of enterprises that have introduced new or significantly-improved products that were new to the market;

- share of enterprises which have introduced new or significantly-improved products that were only new to the firm;

(3) The output indicator group is about the economic effects of innovation [4] and is characterized by the following indicators:

- growth value added in the transport sector;

- growth employment in the transport sector.

Data for the single indicators have been collected for the 261 European NUTS-2 regions. To meet the above described needs of comparability of the heterogeneous European regions, they have been divided into the three groups of less-developed (65), transition (48) and more-developed regions (148) (see Section 2). For each single indicator, values were calculated within each of the three groups as share of the groups' average, which is in line with the original method of IUS and RIS. Values of each indicator have been standardized to allow a better comparison. Finally, the summation of all indicators builds a general score of "innovation potential in transport", as shown in Fig. 2. Consequently, the assumption is that the higher the innovation potential of a region is, the bigger the score will be. While the general score provides a general ranking about the sum of innovation aspects, single indicators allow the user to analyse specific aspects of the innovation potential in detail, serving as a basis to support further interpretation of the preliminary results described in this paper.

The above listed indicators can not only be analysed one by one or as a total score (Fig. 2); The indicators were also grouped according to the above

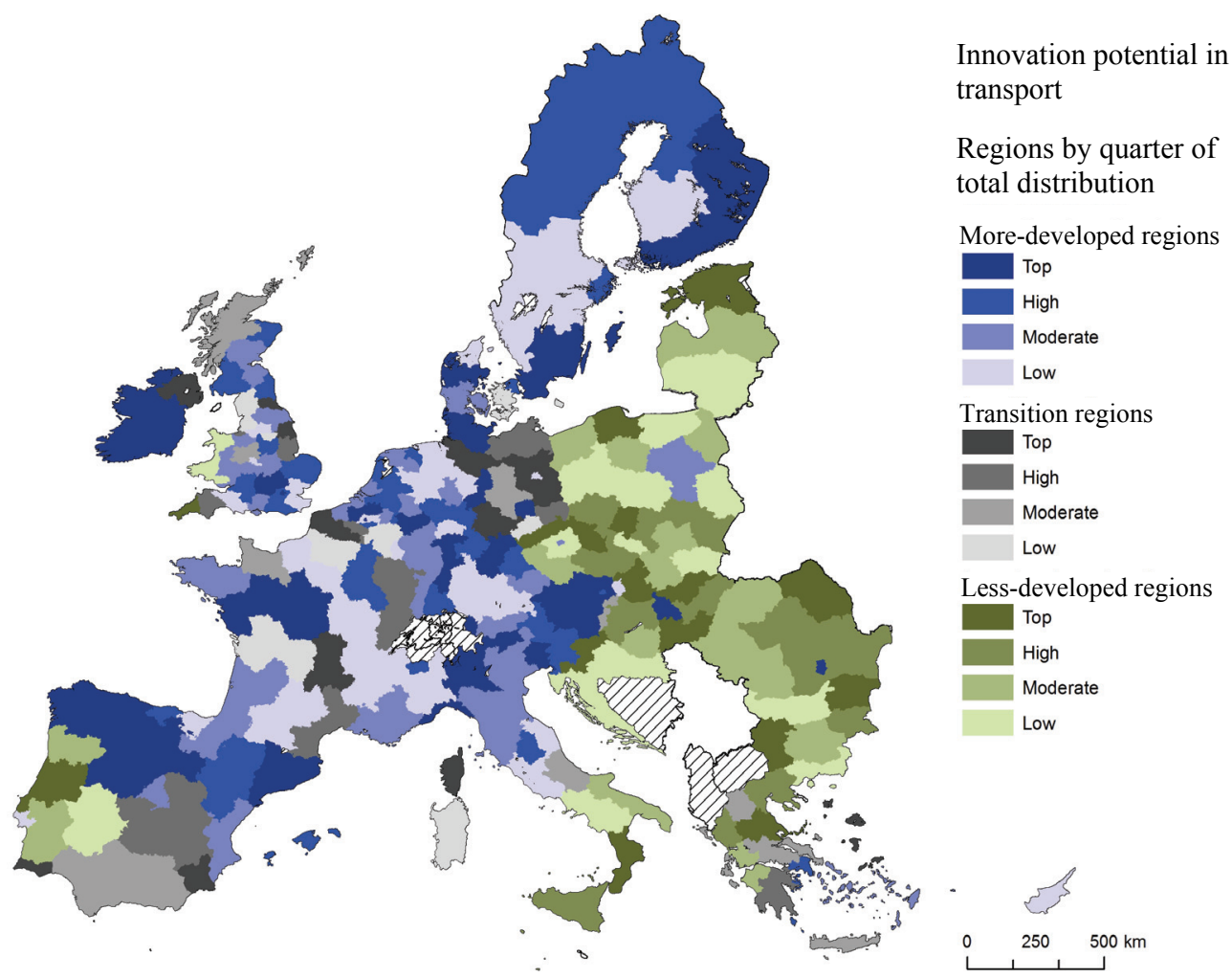

Fig. 2 Innovation potential in transport. 
described classification of: (1) enablers; (2) firm activities; (3) output.

\subsection{Main Principles of Regional Innovation in Transport}

Based on a factor analysis, innovation indicators and variables describing regional economic and socio-economic frame conditions have been analysed in order to identify principles of innovation. Factors have been identified describing related aspects of innovation, e.g., the role of education with related factors showed up as one main principle characterising regional innovation potential and capacity. The work is related to analysis of innovation performance [6], other innovation indicators [7] and innovation milieu [8].

\subsection{Regional Innovation Types}

A typology of regions has been developed using cluster analysis based on 28 indicators describing innovation, regional frame conditions for economy and the transport sector, such as infrastructure, economic development etc. Indicators were defined to explain clusters and represent reality by using economic and socio-economic variables combined with innovation indicators of the regional innovation potential.

\section{Regional Innovation in Transport}

\subsection{Regional Innovation Potential in Transport}

Based on the RIS, indicators for the transport sectors have been developed reflecting innovation enabling, output and activities on a regional basis (see Table 1). Summarized values of the full indicator list provide an overview of the regional innovation potential in Europe.

These were classified in quartiles of the particular group of economic development level. The $25 \%$ of highest ranking regions within each of the groups of "more-developed", "transition" and "less-developed" regions are labelled as "top", and the next $25 \%$ are classified as "high", followed by the next $25 \%$ in the "moderate" and the last quarter in the "low" group. Although the different economic levels have been considered by distinguishing between different groups according to their level of development, the general score still shows the heterogeneity of Europe in terms of transport innovation potential. All categories of "top", "high", "moderate" and "low" potential are spread throughout Europe, although some innovation clustering structures can be discerned.

Spatial patterns of innovation structure and characteristics of different regions can be identified, giving initial ideas for regional types of innovation potential in transport to be analysed more in detail in a further step:

- Regions in the Benelux countries and Northwest Germany are characterized by an established science and research system supported by centres, international networks and the connection between public institutions, research and the private sector. A developed, regionally-embedded, innovative system serves as an economic engine-Innovation as an economic factor itself appears highly differentiated and specialized;

- Regional innovation potential along the Turin-Vienna axis shows a focus on cluster, forced by institutions, such as R\&D centres or technology parks and state funding. The industrial specialization is especially linked to the automotive sector;

- Regions in a triangle between Warsaw, Prague and Budapest show regional innovation potential characteristics with a concentration on main cities as both centres of research and centres of research funding, as well as a high relevance of SMEs (small and medium enterprises) in the innovation context;

- The Nantes-Paris axis shows similar characteristics to Turin-Vienna, where additional factors, such as the support of SMEs and international relevance of established clusters, are also emphasized; 
- The Barcelona-Strasbourg-Dresden axis is characterized by clusters, especially automotive and supplier industries, and supports for clusters. Even solid regional economic structure and a dynamic approach are a given in these regions-Innovation is still supported by focused strategies, investments and innovation infrastructure (institutions);

- The London-Newcastle axis is similar to many other regions-It is mainly based on clusters with international links. Innovation is politically supported;

- The Greater-Bucharest area is characterized by funding of R\&D in SMEs and logistics/transport supported by the active formation of clusters and infrastructure, such as technology parks;

- Innovation in Estonia is related to the long-term support of innovation, reflected especially in innovation firm activities and enabling factors;

- Irelands' innovation is also cluster-based and has international project involvement with the development of innovation potential as a long-term strategy. The economic environment in many regions has a focus on R\&D, especially where SMEs are active in research.

\subsection{Main Principles of Regional Innovation in Transport}

The regional innovation analysis aimed to identify main principles for innovation in transport which are applicable to all regions and which should serve as guidelines for innovation strategies.

These principles include not only innovation aspects but also enabling factors on a regional level identified by a factor analysis performed with variables

Table 1 Regions with high innovation potential.

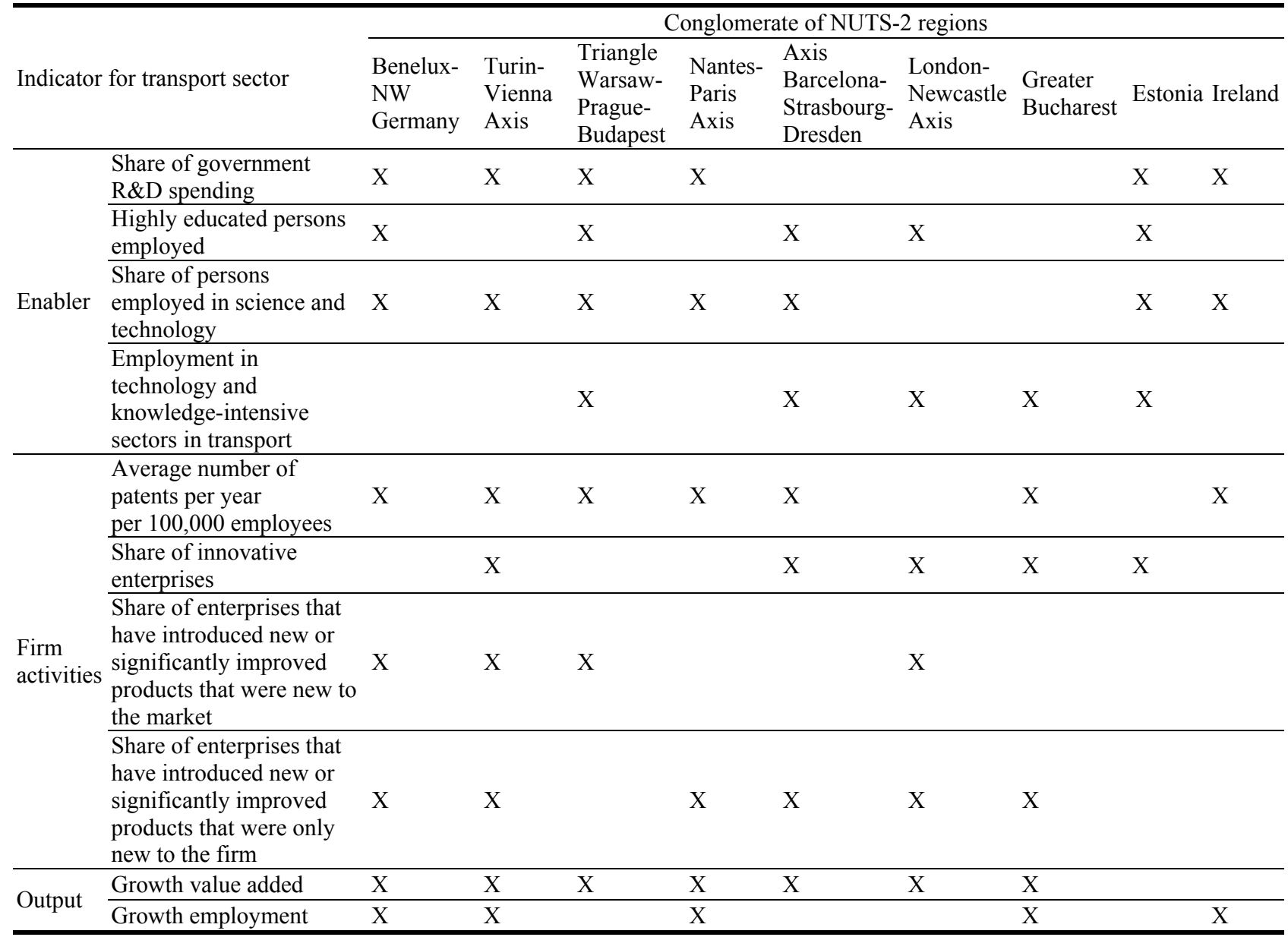


describing regional economic structures and their frameworks, as well as socio-economic aspects and the above-mentioned variables of innovation. Factors form groups of correlating aspects allowing the capture of characteristic patterns of economic and socio-economic innovation-related aspects in the occurrence of innovation and "non-innovation". Different factors designate different combinations related to success in innovation. Several principles related to innovation potential have been identified. Although causality cannot be uniquely determined, the correlation between innovation potential measured by previously described variables can be linked to certain aspects which might influence, support or accompany innovation of transport on a regional level:

- Company size is related to innovation potential on a regional level, although innovation might be situated in small and medium enterprises located in the surroundings of big companies. A reason, which would need further investigation, might be big companies that serve as economic growth engines affecting innovation activities in the regional industry. This is of great importance as the qualitative analysis showed that innovation funding is often focused on SMEs. Links of SMEs to large companies have to be taken into account in the regional context of innovation;

- Public funds for R\&D and financial proportion of $R \& D$ in the region/enterprise are related to innovation, leading to the conclusion that innovation needs investment whether from policy or public sector. Regions along the identified European axis of innovation often host special locations for innovation, such as centres or technology parks, partially linked to regional clusters. Such infrastructure might serve as "innovation cores" for further development. Therefore, initial structures of this kind should be identified;

- Specialization of industries is related to innovation providing a two-way interpretation:
Specialized industries might be a precondition for innovation, while, in turn, innovation might be necessary to sustain specialized companies by renewing uniqueness in products, services and processes, thereby enabling competitiveness. In this context, networks and links appear to be a key issue, especially if clusters have been developed. The qualitative analysis demonstrated connections between innovative regional axis and links on different dimensions, such as public private partnership, clusters as intra-economy networks and international integration;

- Level of education can be interpreted as a precondition of innovation providing a high-skilled labour force. At the same time, education level reflects the labour market and socio-economic levels of the region. Thus, an education enabling regional business climate is related to this aspect;

- Teachers and employees in technical/scientific professions point to the fact that innovation in transport, as measured, is closely linked to science and technology. This serves as a precondition for the innovation-oriented regional economy, which, in turn, attracts a corresponding labour force. This aspect is closely linked to regional economic structure, pointing to the importance of the exchange, links and transfer between education and employment, where the issue of funding might also be an influencing factor;

- A dense transport network accompanied by innovation potential could also be interpreted as a characteristic of an established, mature economic region;

- Proportion of innovative companies seems to be an obvious aspect related to high innovation potential. On the other hand, this leads to the conclusion that innovation is related to and driven by certain companies leading to a high innovation potential, while others, maybe the majority of companies, are not actively innovating.

Alongside the related aspects, correlations of innovation and funding with aspects of economic 
success have also been found, e.g., a low unemployment rate. Innovation activity goes along with a dynamic economy: Innovation is beneficial for the regional economy overall. Another main aspect of maintenance of innovation activities appeared: Even established, highly innovative regions invest continuously in innovation, either from the private economy side or through public funding.

\subsection{Regional Innovation Types}

Besides regional innovation potential of the transport sector and main principles of innovation, regional innovation types should be identified in order to focus funding related to specific innovation potential. The types have been identified by a cluster analysis based on economic and transport related indicators, which should reflect the specific situation of the transport sector by putting it in the context of the regional economy at the same time. Although not all resulting clusters referred to specific characteristics related to innovation, certain types were found.

\subsubsection{National Economic and Innovation Regime}

Some types of regions are concentrated in mainly one country, reflecting a strong impact of national frame conditions (Fig. 3). It is possible that the dominance of national innovation policy and milieu and funding schemes on innovation or transport are not the only factors which could explain this: National characteristics of industry, economic situation and the history of the transport sector are also likely explanations. Thus, path dependency appeared as an important factor influencing regional innovation potential in the transport sector. This effect, however, was more obvious in countries with established industries, especially production.

The French type includes France, Aragon (Spain) and Attiki (Greece) as the only non-French region. The type is characterized by low population density, land use for service and residential purposes and a share of households in densely populated areas falling below the European average. Factors, such as few product placements on the market, resulting from innovation activities in the transport sector and an average cooperation between innovative transport companies and large enterprises are indications that the innovation activities generate little output. A high income and GDP, good infrastructure and a strong employment growth in the transport sector show that this region type is growing economically strong, especially in the transport sector, more due to above-average production than to innovation activities. Further, there is a strong support of R\&D, as the share of R\&D funding is high. In a European comparison, this type of region has an average innovation potential which is based on a strong economy and increasing employment in the transport sector but on few innovation outputs and on average cooperation between innovative transport companies and large enterprises.

Transport innovation regions are located in Central Europe in Germany plus the French region "Auvergne". Besides economically strong cities, such as Munich or Hamburg, this type includes regions, such as "Brandenburg" or "Oberfranken", with a weak infrastructure and a low population density. In general, wealth/income and employment rates are above average, indicating a high level of employment and social welfare. A high GDP and many patents applications and $\mathrm{R} \& \mathrm{D}$ expenditure ensure that this region type can be counted among the economically strong and innovative region types. In addition, large innovative transport companies provide many product placements on the market, and a large proportion of internal R\&D subsidies and growth of value show that the transport sector can be counted as a major strength of this region type. The values of internal R\&D funding, patent applications and growth in value added are (far) above average and the highest of all region types, reflecting a high innovation potential.

Mid-South Europe regions consist of Italy plus the Austrian region "Burgenland" as the only non-Italian region. This type is characterized by a somehow contradictory economic structure with a high GDP, 
despite average employment rate and a high risk of poverty. A high proportion of innovative enterprises with many product placements and high growth in value added and average growth in employment in the transport sector shows that the transport sector is prosperous and innovative. On the other side, the economy in general is not very innovative, since both patents and R\&D activities and funding are below average. Wealth and income are at the European average, but levels of education are low, with a below-average share of persons with tertiary education.

With the known economic division of Italy - a highly industrialized northern Italy and a predominantly agricultural southern Italy - and the results of the regional analysis, it can be assumed that this region type is partially economically strong in the north of Italy, but all regions together represent an average economic strength. General innovation is developed in a rather weak manner, while the innovation performance of the transport sector is rather strong. In the formation of this region type, low share of tertiary education, low infrastructure and low internal $R \& D$ funding (in the transport sector) were particularly important. Concerning innovation potential in Northern Italy, thanking to a very strong and innovative transport sector, a high GDP and level of education and major research expenditure lead to a relatively high general innovation potential, while southern Italy has, due to a lower GDP, poor educational attainment and high unemployment rate with a significantly lower level.

4.3.2 Stage of Economic Development and Position in National Economy

Besides types mainly characterized by country membership, other types reflect the level of economic development or position/function in a national economy (Fig. 4). For example, some European metropolitan and old industrial regions show similar levels of innovation potential in transport, which can be explained by the role of the transport sector related to the general economic structure of the country.

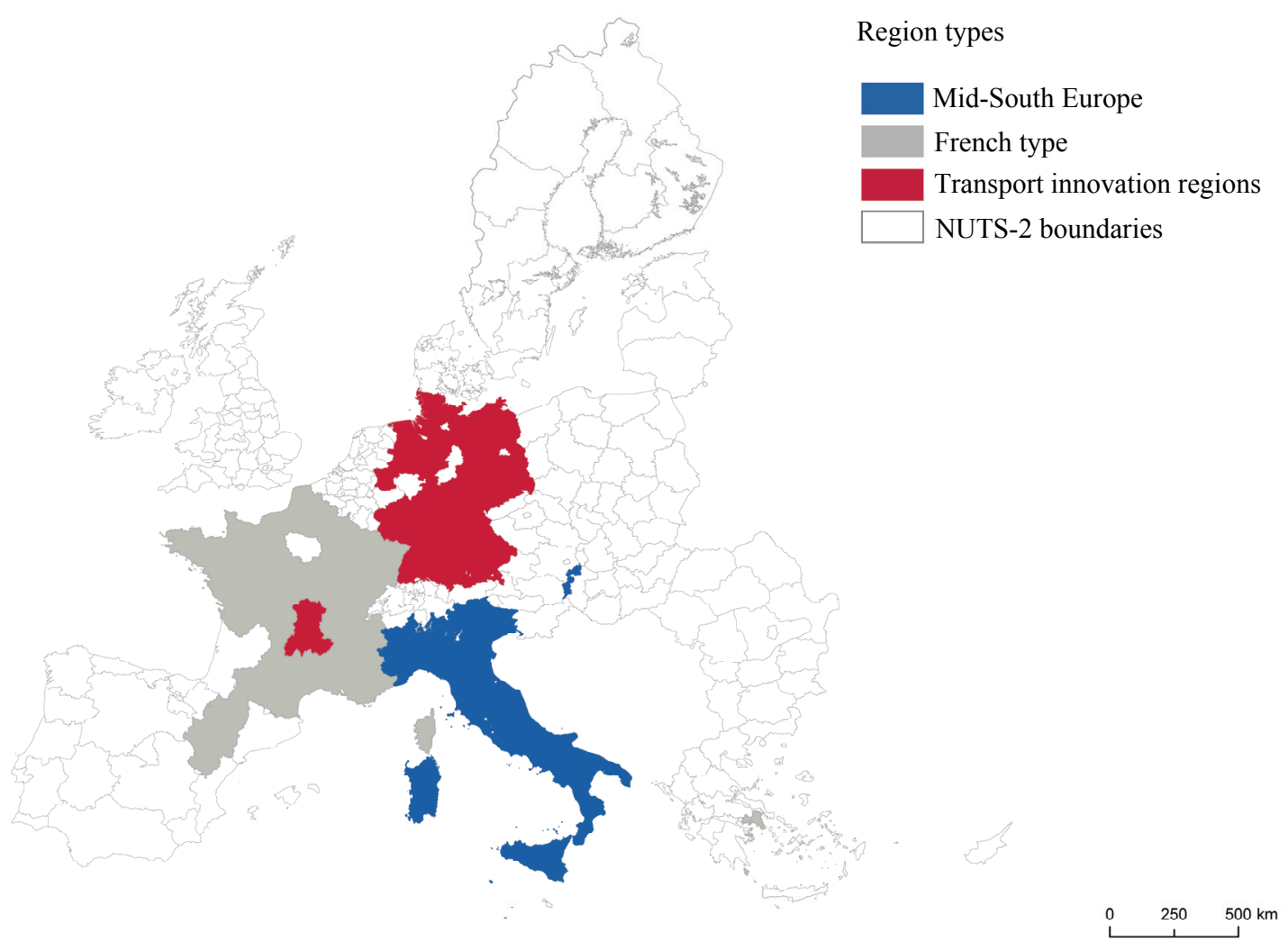

Fig. 3 Regional innovation types characterized by national economic and innovation regime. 


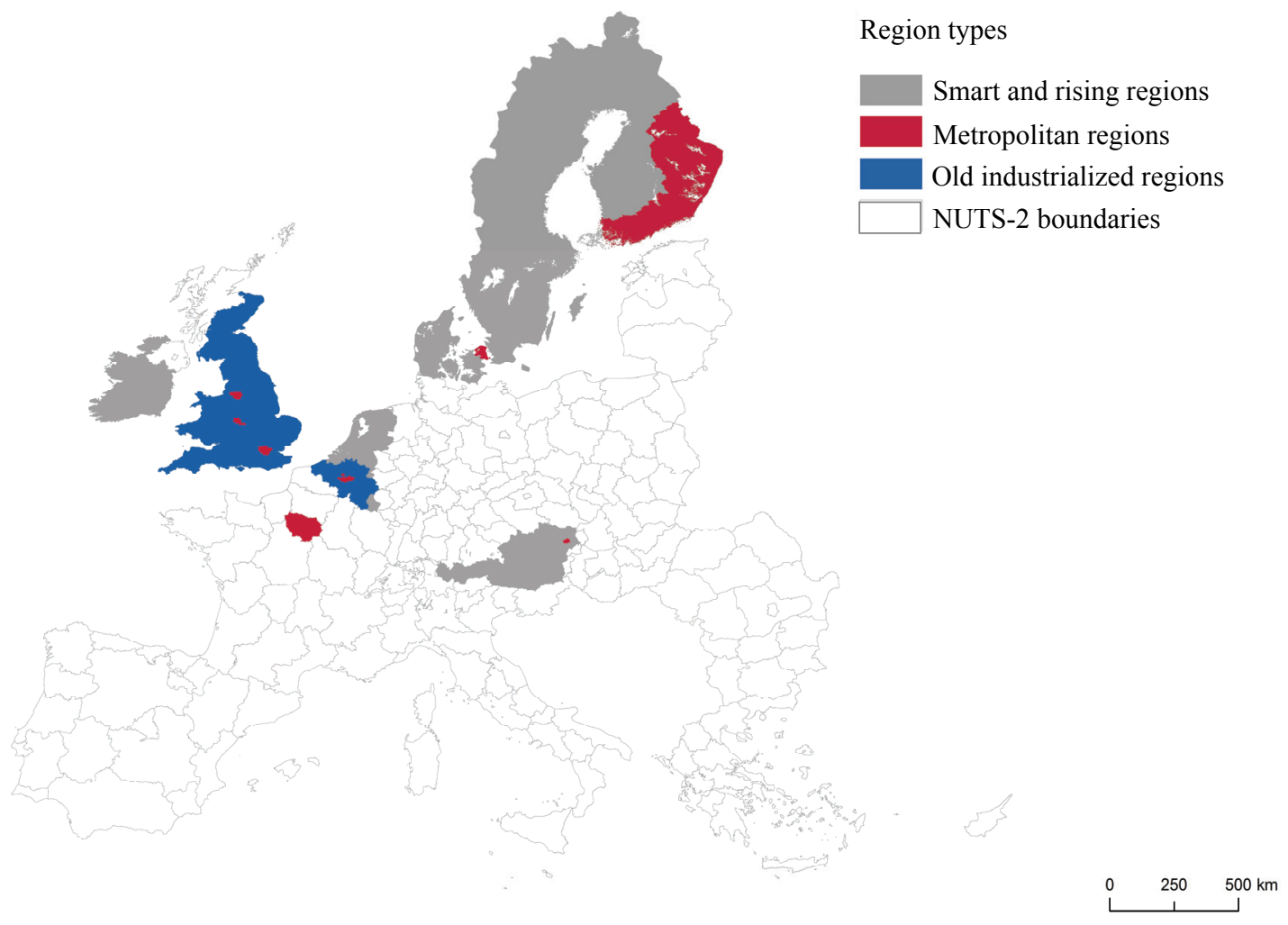

Fig. 4 Regional innovation types characterized by stage of economic development.

Smart and rising regions are located in Northern and Central Europe, namely Austria, Denmark, Finland, Ireland, Luxembourg, Netherlands, Slovenia and Sweden. A high employment rate, low poverty-risk, high-income and wealth of the inhabitants were important in the formation of this type, reflecting a strong economy. A high proportion of workers in science and technology, R\&D funding with many product placements, and far-above European average patent applications show the relevance of science and technology, including innovation and the resulting output, leading to a high general innovation potential. According to the quantitative RIST analysis, in this type of region, some regions are found which have a very high potential for innovation in the transport sector, which then has a supportive effect on the general innovation potential. This relates to the regions in Ireland, Turin, Vienna, Belgium, Luxembourg and the Netherlands [9].

Metropolitan regions include densely populated regions located in Central and Northern Europe:
Helsinki, ${ }^{1}$ Paris, London, Brussels, Vienna and Manchester, consisting of metropolitan regions without their surroundings, which explains the absence of other cities in this region type, such as Berlin, Rome or Barcelona embedded in greater regions.

A high GDP paired with a dense infrastructure characterises the economic strength of this region type. Further, the wealth/income and the proportion of the population with tertiary education are high, reflecting prosperity and a high level of education. Furthermore, there are many patent applications and workers in science and technology, combined with high R\&D spending. This shows that this regional type is a strong innovator and generates corresponding output. A high level of education, GDP, number of patent applications, employees in science and technology and funding of R\&D indicate a high general innovation potential, but the transport sector in this

${ }^{1} \mathrm{Helsinki}$ is part of Karelia, a rural region with low population density. 
type of region is almost completely irrelevant. The decline in employment and value added in the transport sector and few product placements and innovative companies in the transport sector show that, in this region type, innovation in the transport sector plays a minor role.

Old industrialized regions are located in Central and Northern Europe in Belgium and the UK without the metropolitan regions.

This region type has a high proportion of employees in science and technology, a high tertiary education level and wealthy population, reflecting a highly-skilled labour market. On the other side, a low GDP, average employment rate and income are indications of rather average economic power. In transport, the loss of value added and the low employment growth along with an average number of innovative transport companies and product placements into the market shows that the transport sector is rather weak in terms of innovation and economic power. A low GDP with a high level of education, many employees in science and technology and low unemployment rate indicate a rather average to above-average general innovation potential, which is not yet realized, as output indicators show.

This region type is averagely populated with a well-developed infrastructure. In the formation of this region type, average youth ratio, intense cooperation between enterprises and average public R\&D funding in the transport sector were particularly important.

4.3.3 Economic Cycle and Structural Change

A third method of differentiation for regional types of innovation in transport is related to the stage of economic development cycle or reflecting structural change and/or crisis (Fig. 5). Regions at the periphery of the EU in Eastern Europe, Portugal, Scotland or Greece particularly reflect this pattern.

New EU countries are characterized by below-EU-average economic strength, GDP values and $R \& D$ expenditures, as well as a low number of workers in science and technology. The population in this region type has a low level of income and higher

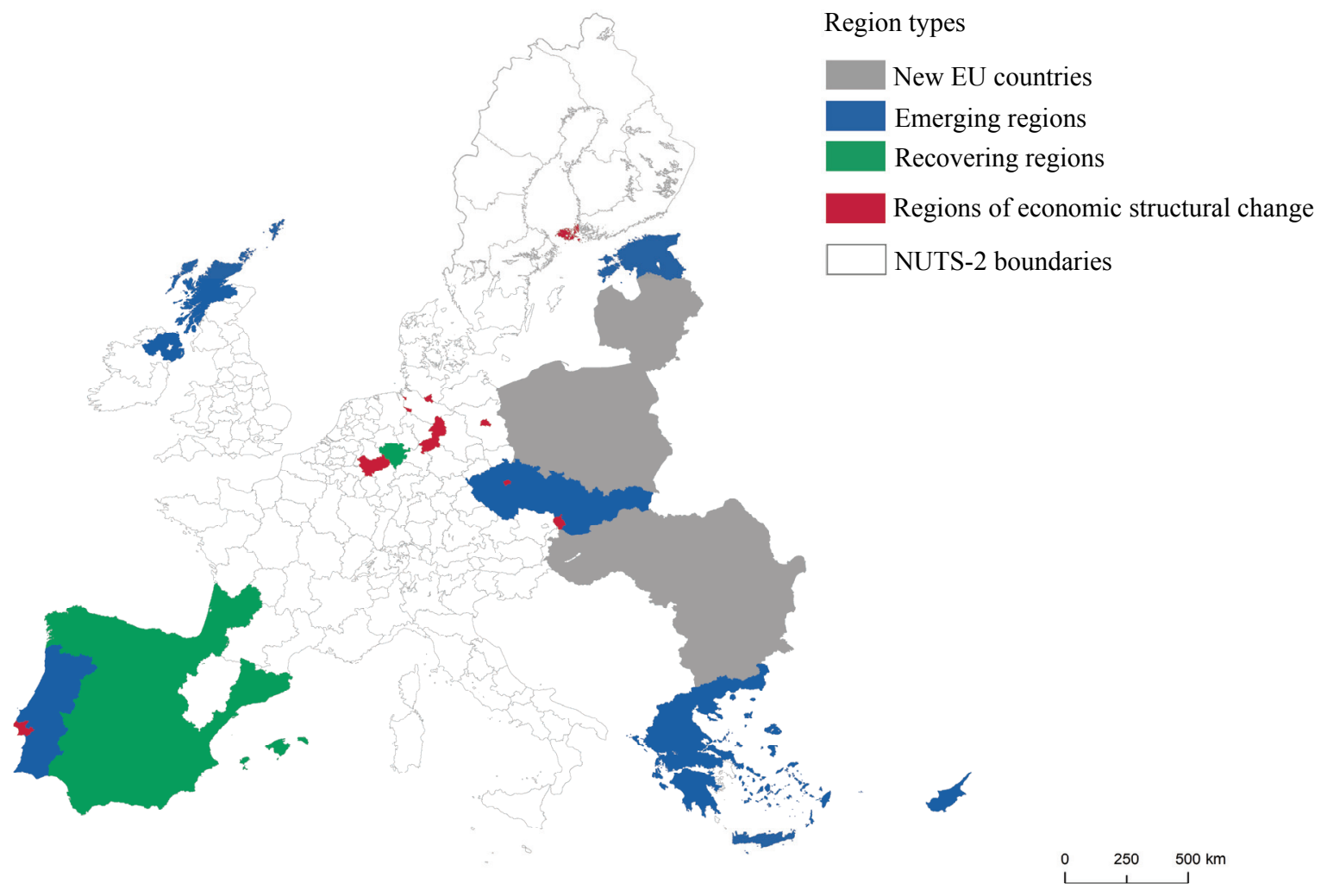

Fig. 5 Regional innovation types characterized by economic cycle and structural change. 
education. The low population density and road/rail/waterways infrastructure, including resulting lower share of land use for living and working, reflect the rural character of this type. A below-EU-average proportion of R\&D investment, patent applications and innovation reveal a higher importance of production over innovation in the transport sector. In the formation of this region type, low patent activity with few applications and low income/assets were particularly important.

Emerging regions have a low general innovation potential, but an economically strong transport sector. GDP values and R\&D expenditures below the European average and low numbers of workers in science and technology indicate an economically weak region type. The population in this region type has partly a low income and a low share of highly-educated workforce since income, as well as tertiary educational attainment, is low. The low population density, infrastructure and share of land use for service and residential indicate more rural regions. High unemployment and the low share of R\&D combined with transport companies, which cooperate often, and a high growth in value added in the transport sector show the strength of this sector with a high relevance for the region but still low innovation potential. In the formation of this region type, few patent applications, low population density and low public R\&D funding (in the transport sector) were particularly important.

Recovering regions are characterized by an employment rate and income around the European average, a high GDP and an average economic strength dealing with a high risk of poverty. A small proportion of innovative transport companies, few product launches and a negative growth in value added in the transport sector, combined with low R\&D funds and less cooperation, leads to a weak innovation performance in the transport sector, while innovation potential of the economy in general lies on average. The high rate of unemployment and employment growth in the transport sector and the strong negative change in the value added in the transport sector are striking. These strong stand-out values show why this region type has suffered greatly from regression, but now some sectors, such as the transport sector, are once again increasing in strength and economic development is positive-More workers are again engaged in the transport sector. In the formation of this region type, small-size enterprises, average internal product launches and low internal R\&D funding (all in the transport sector) were particularly important.

Regions of economic structural change are located over the whole of Europe: the Czech Republic, Finland, Germany, Portugal and Slovakia. This region type consists mainly of large cities without metropolitan regions with high population density, a high proportion of households in densely populated areas, high $R \& D$ expenditure and a high GDP, reflecting economic strength and, together with many patent applications, a high general innovation potential. The population is wealthy with a high level of education and low poverty risk. A high proportion of innovative and large transport companies with a lot of product placements into the market due to innovation output in the transport sector and high internal R\&D subsidies and growth in value added are indications that the transport sector is strong, which relates to its economic power, innovation activities and output. Nevertheless, the infrastructure (motorways, waterways and railways) is rather weak and the proportion of public funding in the transport sector is low.

This region type has above-average values regarding the transport sector in internal $R \& D$ funding, product placements within transport companies, company size and growth of value added. This region type also includes old industrial areas which have undergone a structural change and have a strong economic growth, particularly in the transport industry and attract know-how. However, since the 
employment rate in the transport sector decreases along with an outstanding increase in value added, it can be assumed that, in these regions, there is a shift from production to $R \& D$ in the transport sector. In the formation of this region type, average youth ratio, a high disposable income and many innovative enterprises (in the transport sector) were particularly important.

A high innovation potential in the transport sector can be concluded from above-average values regarding the transport sector in internal R\&D funding, product placements within transport companies, company size and growth of value added.

4.3.4 Regional Typology of the European Transport

\section{Sector}

The analysis of regions according to similarities related to innovation points to some main characteristics of innovation in this sector which are relevant for funding through the EU (Fig. 6):

(1) National factors affect innovation of the transport sector, which is reflected in the fact that four of 10 clusters mainly consist of one country: Italy, Spain, France or Germany.

The role of the transport sector in the national economy, history of the sector and path dependency all need to be considered in case of funding;

(2) The current economic situation, especially concerning performance during the financial and economic crisis, is crucial for the development of the transport sector. Different European countries have been affected unequally, which is reflected in transport sector development, especially when it comes to employment or GDP.

Innovation activity is not only a result of transport specific aspects, but depends on general economic development - on varying levels, depending on the country;

(3) Development of the transport sector is path-dependent; The national economic milieu affects the sector. A traditionally strong $R \& D$ aspect in transport leads to the innovative transport region, while

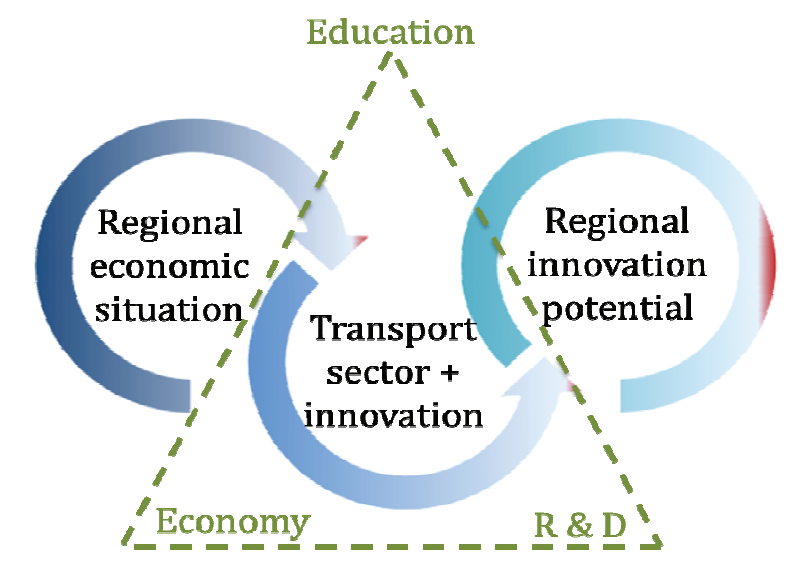

Fig. 6 Innovation fields.

transport as a pure service usually is not correlated with innovation activity. Nevertheless, services are of high relevance.

Innovation in transport should be considered for transport services, having innovation potential in different fields compared to production, e.g., in process innovation or increasing efficiency for energy or emissions.

\section{Conclusions}

Besides identifying European regions with high innovation potential in transport, some of which are already performing well, the preliminary stage of the METRIC analysis reveals open questions and additional challenges.

The first results show an innovation landscape as heterogeneous as Europe itself. Many regions are strong in firm activities without scoring high in the enabling indicators; Other factors, rather than those analysed enable innovation in these regions or their "enablers", do not score especially high, still supporting innovation sufficiently.

Other regions are strong in many or even all of the innovation indices. These regions seem to follow the ideal path of good regional frame conditions, providing a good basis for innovation activities, which in turn leads to beneficial outcomes like job growth.

On the other hand, some regions are supported by a high level of innovation enabling benefits from job 
growth without showing remarkable innovation activity; Investment seems to lead to economic growth in transport without stimulating real innovation activities.

These contradictory findings point out that there is no single innovation path but a more complex connection among enabling factors, actual innovation activity and beneficial, measurable outputs of innovation.

Concerning regional types of innovation in Europe, initial observations show that innovation seems to be a rather nationally-related characteristic, especially in countries with huge innovation potential. Infrastructure of innovation of the transport sector seems to be dependent on national frame conditions, such as investments, funding or cooperation in innovation.

This points to the crucial role of innovation policy or policy affecting frame conditions for innovation.

Besides these patterns of innovation, potential was found distributed throughout Europe, reflecting a certain stage of economic development, such as metropolitan areas or regions under economic transformation.

Results show that history of innovation, economy and industry are all important factors and have to be considered in funding or any innovation support. Building on what is there is more efficient than development from scratch.

Furthermore, innovation in transport appeared to be dependent on both the historical path of economic development of regions and countries and the recent economic situation, which was dominated by financial and economic crisis in recent years.

Innovation is driven (or blocked) by crisis and the need to adapt to changing frame conditions, which is strongly reflected in recent innovation potential.

Innovation potential in the transport service is different to transport industries. Nevertheless, there is a huge potential for process innovation, which could increase energy efficiency and reduce emissions, thereby contributing to European goals.

In order to support these kinds of innovation, further research, new strategies and approaches have to be developed.

Therefore, in order to successfully support innovation, strengths and regional characteristics need to be identified in a first step. Based on this, innovation principles can be chosen, e.g., a focus on education or specialization of regional industry, and can be adapted to the characteristics of the regional transport industries.

In the triangle of education/skills, R\&D and economy/enterprises, which is based on main principles of innovation, the fields of regional economic situation and innovation potential, as well as innovation in transport (or other industries), need to be considered. This step of analysing regional strengths and weaknesses requires the development of an in-depth understanding of the position: knowledge of the economic path dependency of a region and identification of a reality-based innovation potential beyond wishful thinking. The described method through RIST developed in the METRIC project helps to provide an approach to analyse the regional situation based on statistical data.

The crucial role of investment in innovation in the triangle was one of the main results of the analysis. Whether from policy or the private sector, funding for innovation needs to address these fields in a consistent way.

Further, there is still the potential for building synergies between the three fields, e.g., by encouraging strong links, exchange and cooperation between the regional economy and regional education system (universities and applied universities through to secondary school level). Good governance, ways of cooperation between regional actors, supporting regimes and institutions and funding schemes to link these three areas still have to be developed-A field where innovation at the institutional level is still required. 


\section{References}

[1] European Commission. 2011. Roadmap to a Single European Transport Area-Towards a Competitive and Resource Efficient Transport System. White paper. European Commission.

[2] Gnyawali, D. R., and Srivastava, M. K. 2013. "Complementary Effects of Clusters and Networks on Firm Innovation: A Conceptual Model.” Journal of Engineering and Technology Management 30 (1): 1-20.

[3] European Commission. 2013. Innovation Union Scoreboard 2013. Brussels: European Commission.

[4] European Commission. 2013. Refocusing EU Cohesion Policy for Maximum Impact on Growth and Jobs: The
Reform in 10 Points. Brussels: European Commission.

[5] European Commission. 2012. Regional Innovation Scoreboard 2012. Brussels: European Commission.

[6] Konings, R., and Louw, E. 2014. Transport Research and Innovation Performance of Regions. Brussels: European Commission.

[7] Maras, V., and Radmilovic, Z. 2014. Mapping Regional Transport Innovation Frameworks. Brussels: European Commission.

[8] Maras, V., and Radmilovic, Z. 2014. Innovation Milieu in European Regions. Brussels: European Commission.

[9] Hoppe, M., and Winter, M. 2014. Matrix of Main Principles for Regional Transport Innovation. Brussels: European Commission. 